operating on all patients diagnosed with ALCA while calling into question the utility of this approach for patients with asymptomatic ARCA.

For those who have no symptoms, an exercise stress test is usually performed to demonstrate evidence of ischemia. These data help guide clinical decision making regarding whether to proceed with surgical intervention. As recommended in the most recent Bethesda guidelines, physicians also use postoperative exercise stress testing before allowing a patient to return to exercise. ${ }^{5}$ Our concern is that ischemia is intermittent in AAOCA. Our patient with ALCA clearly had evidence of ischemia on one exercise test and a normal result just 1 week later. Symptoms of ischemia were not reliable, because the patient was free of symptoms during both tests. Our patient could by chance have had two normal test results and never had his ALCA diagnosed, possibly until a sudden catastrophic event occurred. Indeed, more accurate measures of ischemia are needed in this population. Until then, use of exercise tests as the sole indicator of ischemia for both preoperative and postoperative decision making should be questioned.

\section{References}

1. Basso C, Maron BJ, Corrado D, Thiene G. Clinical profile of congenital coronary artery anomalies with origin from the wrong aortic sinus leading to sudden death in young competitive athletes. J Am Coll Cardiol. 2000;35:1493-501.

2. Frescura C, Basso C, Thiene G, Corrado D, Pennelli T, Angelini A, et al. Anomalous origin of coronary arteries and risk of sudden death: a study based on an autopsy population of congenital heart disease. Hum Pathol. 1998;29:689-95.

3. Maron BJ, Doerer JJ, Haas TS, Tierney DM, Mueller FO. Sudden deaths in young competitive athletes: analysis of 1866 deaths in the United States, 1980-2006. Circulation. 2009; 119:1085-92.

4. Brothers JA, McBride MG, Seliem MA, Marino BM, Tomlinson RS, Pampaloni $\mathrm{MH}$, et al. Evaluation of myocardial ischemia following surgical repair of anomalous aortic origin of a coronary artery from the opposite sinus of Valsalva in a series of pediatric patients. J Am Coll Cardiol. 2007;50:2078-82.

5. Graham TP Jr, Driscoll DJ, Gersony WM, Newburger JW, Rocchini A, Towbin JA. Task Force 2: congenital heart disease. J Am Coll Cardiol. 2005;45: 1326-33.

\title{
Primary thoracic cavity gastrointestinal stromal tumor
}

\author{
Ji-Wei Cheng, MSc, ${ }^{\text {a }}$ Shao-Hua Lu, MD, ${ }^{\mathrm{b}}$ Song-Tao Xu, MD, ${ }^{\mathrm{a}}$ Hao Wang, MD, ${ }^{\mathrm{a}}$ Ying-Yong Hou, MD, \\ $\mathrm{PhD},{ }^{\mathrm{b}}$ Ru-Heng Zheng, MD, and Yun-Shan Tan, MD, ${ }^{\mathrm{b}}$ Shanghai, China
}

Gastrointestinal stromal tumors (GISTs) are mesenchymal tumors that mostly arise in the gastrointestinal tract. Other locations such as the omentum, the mesentery, and the retroperitoneum have also been reported. Here we report a rare case of primary thoracic cavity GIST. Although this rare tumor may be difficult to distinguish clinically from more common mass lesions of the thoracic cavity, a correct diagnosis is necessary because treatment is specific for GIST.

\section{CLINICAL SUMMARY First Operation}

A 62-year-old female patient was hospitalized with a 6-month history of common cold symptoms in September 2007. Her medical record and family history were unremark-

\footnotetext{
From the Departments of Thoracic Surgery ${ }^{\mathrm{a}}$ and Pathology, ${ }^{\mathrm{b}}$ Zhongshan Hospital, Fudan University, Shanghai, China

Disclosures: None.

J-W. Cheng and S-H. Lu contributed equally to this study.

Received for publication Oct 26, 2009; revisions received Dec 24, 2009; accepted for publication Jan 1, 2010; available ahead of print April 12, 2010.

Address for reprints: Ying Yong Hou, MD, PhD, Department of Pathology, Zhongshan Hospital, Fudan University, 180 Fenglin Rd, Shanghai 200032, China (E-mail: houyingyong@medmail.com.in).

J Thorac Cardiovasc Surg 2010;140:e29-31

$0022-5223 / \$ 36.00$

Copyright $(c) 2010$ by The American Association for Thoracic Surgery doi:10.1016/j.jtcvs.2010.01.005
}

able. The x-ray film showed a dense shadow in the middle and lower lobes of the right lung (Figure 1, $A$ ). Computed tomographic scan of the chest revealed a huge heterogeneous mass in the right thoracic cavity, the mediastinum and the heart were pushed to the left, and no mediastinal lymphadenopathy was found (Figure 1,B). There were no other abnormalities by physical examination or laboratory testing.

The patient was then scheduled for surgery because of suspected lung neoplasm. At thoracotomy, there was an $800-\mathrm{mL}$ reactive benign pleural effusion. The tumor was attached to the diaphragm through a $2-\mathrm{cm}$ pedicle and invaded the right lower lobe of the lung but did not involve the esophagus or other mediastinal structures. After the adhesion had been separated from the lung, it was resected en bloc with a portion of the diaphragm.

The tumor was covered with a pseudocapsule except for the site where the tumor was attached to the diaphragm with a gray-white mass measuring $20 \times 15 \times 10 \mathrm{~cm}$. Microscopically, the tumor was predominantly composed of spindle-shaped cells with a moderate degree of nuclear pleomorphism. Immunohistochemical studies revealed the tumor cells positive for alpha smooth muscle actin and CD34, focally positive for desmin. Considering the origination, morphologic features, and immunohistochemistry of the tumor, leiomyosarcoma was finally reported. 

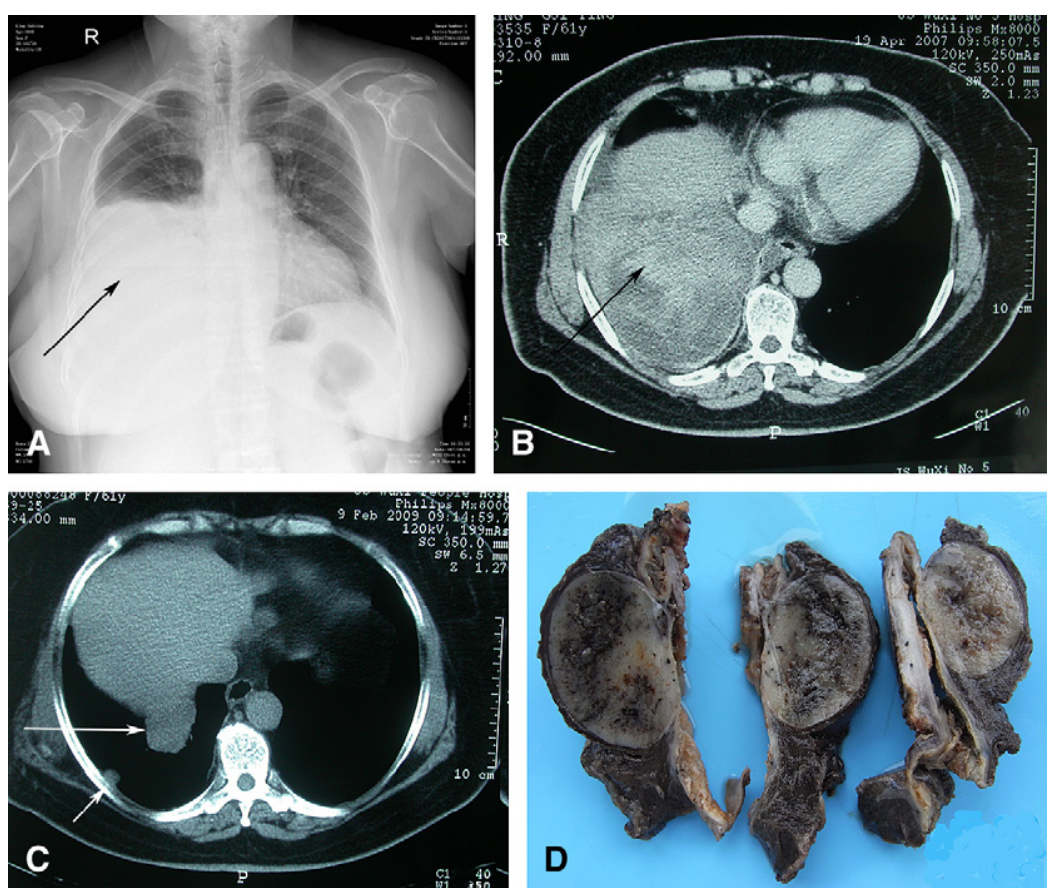

FIGURE 1. A, X-ray film showed dense shadow in the middle and lower lobe of the right lung. B, Computed tomographic scan depicting a huge heterogeneous mass measuring $14.2 \mathrm{~cm}$ anteroposteriorly, $13.2 \mathrm{~cm}$ transversely and $16.4 \mathrm{~cm}$ craniocaudally in the right thoracic cavity. C, Computed tomographic findings. A large tumor (long arrow) of $5 \mathrm{~cm}$ in diameter involved diaphragm and diaphragmatic surface of the right lower lung. A small tumor (short arrow) of $1 \mathrm{~cm}$ in diameter was in the lateral segment of the right lower lung. D, Gross findings of the resected tumor. The tumor was white in cut surface and had a clear boundary with lung tissue, measuring $5 \times 4 \times 4 \mathrm{~cm}$ in size.

The tumor was completely resected. With no adjuvant therapy, the patient was disease free for 17 months until recurrent tumor was found in the right thoracic cavity during a regular check-up by computed tomographic scan (Figure $1, C)$.

\section{Second Operation}

On the basis of the first pathologic examination, the surgeons decided to resect the recurrent tumor because leiomyosarcoma is insensitive to chemotherapy. At thoracotomy there were two tumors in the right thoracic cavity: one was $1 \mathrm{~cm}$ in diameter in the lateral segment of the right lower lung, and the other was $5 \mathrm{~cm}$ in diameter involving the diaphragm and diaphragmatic surface of the right lower lung. Right lower lobe lobectomy was performed with wedge resection of the lung together with the two tumors, as well as diaphragmatic resection and reconstruction. Neither tumor involved the esophagus or other mediastinal structures.

The $5 \times 4 \times 4$-cm tumor was white in cut surface and had a clear boundary with lung tissue (Figure 1, D). Microscopically, the tumor had uniform spindle cells with a moderate degree of nuclear pleomorphism (Figure 2, A). The mitotic index was 19/50 in high power fields. Immunohistochemical studies showed positive staining for CD117 (c-kit) and
CD34 antigens, whereas S-100 and alpha smooth muscle actin staining was negative (Figure 2, B). Genetic analyses revealed loss of heterozygosity at codon 567-576 of exon 11 of the c-kit gene accompanied AAG GAA insertion (Figure $2, C) .{ }^{1}$ The present case was positive for CD117 and c-kit mutations, suggesting that it is a true primary thoracic cavity GIST with high-grade malignancy based on the international consensus on GIST. ${ }^{2}$ The postoperative course was uneventful. Imatinib mesylate was recommended for the patient. At present, 8 months after the second operation, the patient is in good health and recurrence free with imatinib therapy.

\section{DISCUSSION}

GISTs are mesenchymal tumors arising mostly in the gastrointestinal tract, with locations in the stomach $(50 \%-70 \%)$, the small bowel $(20 \%-30 \%)$, and the esophagus, colon, and rectum $(5 \%-10 \%){ }^{3-5}$ Primary GISTs outside the gastrointestinal tract are very uncommon. To the best of our knowledge, this is the first reported case of a primary thoracic cavity GIST.

In this case, the tumor was located in the right thoracic cavity and was found not to be adherent to the esophagus during the first operation. The clinical findings of most cases, which suggest the presence of a soft tissue tumor originating from thoracic cavity, led to a false initial diagnosis. 

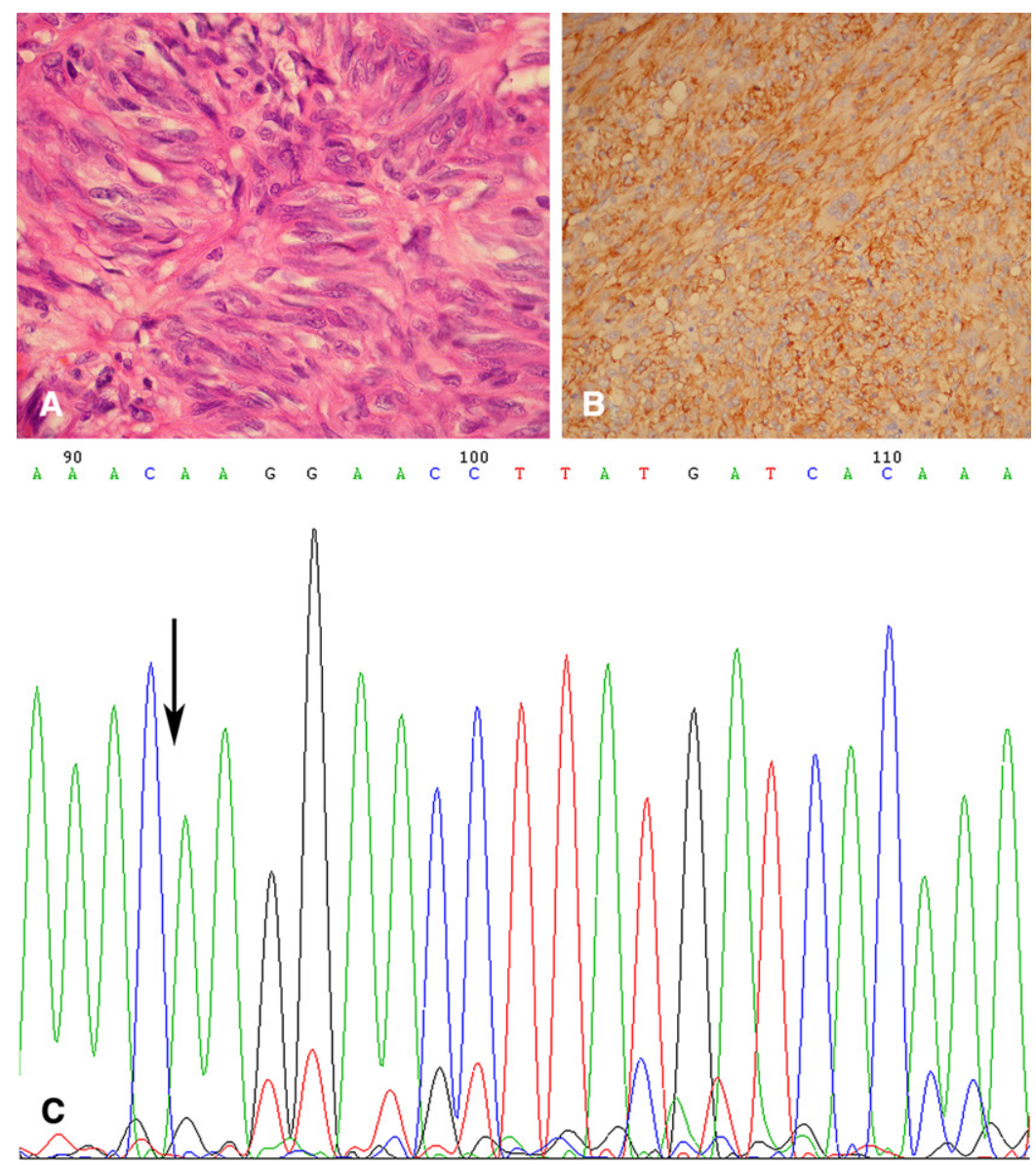

FIGURE 2. A, Microscopically, the tumor had uniform spindle cells with a moderate degree of nuclear pleomorphism. B, Immunohistochemical studies showed positive staining for CD117 (c-kit). C, Genetic analyses revealed loss of heterozygosity at codon (the arrow indicates the beginning mutation locus) 567-576 of exon 11 of the c-kit gene accompanied AAG GAA insertion.

Immunohistochemistry with c-kit is a key tool for correct diagnosis. It is therefore strongly recommended that for unusual spindle cell tumors of the thoracic cavity, immunostaining for kit and CD34 and mutational analysis for kit genes should be performed so as to institute appropriate treatment.

\section{References}

1. Hirota S, Isozaki K, Moriyama Y, Hashimoto K, Nishida T, Ishiguro S, et al. Gainof-function mutations of c-kit in human gastrointestinal stromal tumors. Science. 1998;279:577-80.
2. Fletcher CD, Berman JJ, Corless C, Gorstein F, Lasota J, Longley BJ, et al. Diag nosis of gastrointestinal stromal tumors: a consensus approach. Hum Pathol. 2002; 33:459-65.

3. Pidhorecky I, Cheney RT, Kraybill WG, Gibbs JF. Gastrointestinal stromal tumors: current diagnosis, biologic behavior, and management. Ann Surg Oncol. 2000;7: 705-12.

4. Miettinen M, El-Rifai W. H L Sobin L, Lasota J. Evaluation of malignancy and prognosis of gastrointestinal stromal tumors: a review. Hum Pathol. 2002;33: 478-83.

5. Reith JD, Goldblum JR, Lyles RH, Weiss SW. Extragastrointestinal (soft tissue) stromal tumors: an analysis of 48 cases with emphasis on histologic predictors of outcome. Mod Pathol. 2000;13:577-85. 